\title{
1. Introduction: comity in a global perspective
}

\section{THE INTERNATIONAL SETTING}

We live in a disordered world. We would all prefer to live in a world at peace, where the countries, federations and unions to which we belong all respect common standards of behaviour and a common international law. We would like them to cooperate in solving problems that concern all our futures.

Unfortunately, we do not live in such a world. We live in a world where President Trump tweeted his foreign policy decisions at night in his pyjamas, where the Chinese ruling communist party jails opposition figures on charges of 'corruption' and forcibly 're-educates' its peoples, and where Russia, North Korea, Iran and Saudi Arabia resort to poison, assassination and force.

The international policies of the major players oscillate. They swing between mutual engagement one moment and containment the next, between partnerships and unilateralism, between the impulsive and the calculated, and between lip service to the rule of law and the use of force to achieve their objectives. They are inconsistent actors in an unstable and unpredictable world.

\section{THE CURRENT FRAMEWORK}

There is no shortage of international bodies that could provide focal points for common international action. It is a crowded world, built on different organising principles. It is often criticised as fractured, fragmented and incoherent. However, what is now fatally weakening the international capacity and resolve to act is not the multiplicity of bodies. It is the fundamental disagreements that exist among the 190-plus participants within the memberships of fully international bodies.

\section{THE SOURCES OF DISAGREEMENT}

The main elements in the international structure as we know it were put in place at the end of the Second World War at a unique juncture in history. The allies were united in their desire to rebuild and recover, the United States (US) 
provided an unchallenged leadership and there was a common desire to avoid the weaknesses of the pre-war League of Nations, as well as agreement on the need to avoid self-defeating trade and exchange rate policies. In all too short a time, the critical moment passed, replaced by fundamental disagreements, frozen by the Cold War. Two rival visions of social organisation, with different world views, coexisted in a stalemate of mutually assured destruction. That period too has ended. But the hope that the ending of the Cold War would usher in a new period of global cooperation and a convergence and consensus on norms of behaviour has proved illusory.

We are now at another critical juncture. The disagreements we see in the world today arise partly from the tensions that inevitably accompany any major shift in the relative power of nations. China and India are growing powers. The European Union (EU) wishes to assert itself as a unitary actor and to use its importance as a trading bloc in order to leverage up its weight and influence in other areas of global policy. Russia wishes to reassert itself. The US has become hesitant about carrying the burdens of leadership. At the same time, President Trump damaged both American democracy and America's external alliances.

However, the disagreements that stand in the way of global rulemaking are not just those that inevitably accompany changes in the distribution of power between countries. They reflect, much more importantly, fundamental disagreements over the values that should be applied in rulemaking. The disagreements flow from the different political character of governments and, in particular, depend on whether they are democratic or autocratic. Character matters. If values were shared, we would be very much less concerned by shifts in power.

What gives a dangerous edge to the disruption is that the new rising power of China is autocratic. Alongside an old autocratic power - Russia - it can provide support and cover for smaller autocracies in Central Asia and elsewhere in the world. The values of democracies face a fresh and potent challenge from the outside world at the very same moment when democracies face their own internal challenges in backsliding.

\section{VALUES: THE TECHNICAL AND THE POLITICAL}

For much of the post-war period there has been a deliberate and conscious effort to set aside differences in the domestic character of government and the underlying differences in political values. The domestic character of governments has been treated as a matter of 'sovereignty' and of no concern to other countries or to the outside world. With the major exceptions of peacekeeping and humanitarian assistance, including gross abuses of human rights that trigger a 'duty to protect', much of international rulemaking, from trade 
and finance to food security, health and the environment, has been framed as a separate, largely technical exercise, constructed around function-specific international bodies.

This separation between the principles and values underlying the domestic organisation of governments and functionalism at the international level is now impossible to maintain. The different character of systems of government has become the major obstacle to international rulemaking in the areas where international rules are most required.

The key reason why the separation is now impossible to maintain is that many of the rulemaking issues that arise in new areas of international concern and attention go deeply into domestic policy, law-making and regulation and bring into play the core values underlying the internal organisation of political authority.

We used to think of international rulemaking in terms of rules to manage the exchange of traded goods and commodities and the capital and money flows that made the exchange possible. But now we live in a world where much of what matters in generating exchange is information, intellectual ideas and property, content and knowledge. In the knowledge economy the key medium of exchange is data. The rules thus have to be shaped according to the value we attach to the probity and integrity of data, to privacy, the extent of the private realm, honesty, fairness and the duty of care in contracting, and freedom of expression and association. The uses to which we put information, knowledge and innovation have to respect the person and personhood. If countries do not treat the same fundamental values in the same way in their domestic political arrangements, they will only rarely agree on what values are applicable in international rulemaking.

It is not just a question of fundamental disagreement about what values are applicable. Democratic countries also need to be able to validate the positions they take on rulemaking in international bodies to their electorate. The link is thin. Electorates do not generally pay much attention to what their governments do in international forums. But some degree of consistency between the approach taken to the content of international rules and the underlying suppositions of democratic societies provides the most readily understood connection and form of validation for democratic governments in front of their citizens.

Because the content of international rulemaking now brings into focus the internal political character of different regimes, the majorities required to take decisions in international bodies have become much more difficult to orchestrate. Democratic governments do not want their core values eroded by outside pressures. They not only wish to defend their core values; they also wish to assert them relative to others. At the same time, authoritarian governments have no wish to be exposed, ranked and compared with other countries in 
relation to their basic form of government. Least of all do they want to have their own legitimacy questioned.

There are areas of international rulemaking and cooperation, such as the need to address income inequalities, health and climate change, that appear to transcend underlying differences between the basic political character of regimes. But they too are not impervious to underlying political values. We have seen how an authoritarian communist party in China seems to have suppressed accurate data on the start of the Coronavirus disease in 2019 (COVID-19) in a way that delayed the response to a global pandemic that affected us all. Similarly, it took monitoring stations in South Korean and Japan to detect the production in China of a type of ozone-depleting chlorofluorocarbon (CFC) banned under the 1987 Montreal Protocol to safeguard the ozone layer (to which China itself is a signatory). Power inequalities within authoritarian countries produce wealth and income disparities as pronounced as anywhere in the world.

We now live, therefore, in a world where differences between the principles of government at the domestic level make a profound difference to approaches to the content of rulemaking at the international level, to the willingness of governments to engage with the substance of rulemaking, and to the capacity of international bodies to take decisions. The old Cold War is over, but a new trial between opposing values is now underway. The old Cold War centred on rivalry between different comprehensive world views. The new tensions lack this comprehensive ideological framework. They are about the connection between how power is exercised, justified and validated within societies and how it is exercised at the international level.

\section{TWO FUTURES}

In a world where the principles of government do not reflect shared values, and where, as a result, governments will only infrequently coalesce in their approach to global rulemaking, we can look at two future scenarios.

In one future scenario we can rely on a world without a conductor. We can look to the metaphor of the autonomous, driverless car. We can hope that, despite the problems in making global rules of behaviour, the car will still stay on the road through the uncoordinated efforts of the many actors with a vital interest in predictable international rules of behaviour - actors such as international investors, manufacturers with international supply chains, providers of cashless payments systems, and the providers of internet platforms and their content. We can also look to cooperation between the professionals engaged with the ecology of the planet; the health, safety and education of its population; corporate governance; the probity of capital markets and the rule of law. We can support voluntary international organisations. We can hope for self-restraint by governments. We can hope that instability among smaller 
nations and in politically unsettled regions of the world will not drag in the major powers and their rivalries.

Alternatively, in a different scenario, we can think about new ways, or revive old ways, for achieving international cooperation.

This book examines one such alternative, older, model for achieving international agreements. It does not depend on arriving at global agreements in fully international organisations. It relies on cooperation between like-minded democratic countries. They retain their different jurisdictions and their own authority. But, because they share the same expectations about underlying values and behaviours, they can agree on common rules that each will adopt. Together, individually and collectively, they can try to promulgate these rules in the wider world, side-by-side and, if necessary, in competition with other sources of rulemaking. The approach of side-by-side rulemaking in the same space represents a particular variety of what is generally referred to as 'comity'.

\section{COMITY}

Outside the study of law, 'comity' is not a familiar word. It came into use in the seventeenth century at the time when 'sovereign' states were emerging as the main unit for organising the functions of government, and it addressed the conduct of relations between them. It links to a broader class of settings, both historical and continuing today, where different systems of law coexist alongside each other in an overlapping space. 'Comity' as used in this analysis of the global space refers to rulemaking that coexists between fully international rulemaking and the unilateral projection of rules. It is applied to a system of international rulemaking that is more than unilateral but less than fully international in its making. The term is deployed to refer to a form of rulemaking with an international reach without a fully international basis.

Comity has been chosen as the over-arching organising concept for this book for three reasons. Firstly, it provides a point of entry for a normative perspective on the multiplicity of rules and rule makers we see in the world today. This normative perspective distinguishes it from much orthodox discussion of the 'transnational'. It places the spotlight on the importance of normative ties between rule makers in shaping institutions, relationships and the policy process.

Secondly, comity provides for a focus on the growing departure from a traditional presumption against laws that have external effect - 'extraterritoriality'. It looks at the processes and techniques of domestic rulemaking that have external influence and that provide means of influence, short of the application of force, in the external world. It brings together the range of measures that 
democracies can take to defend their values from external influences reaching in, and that enable them to express their own values and to reach out.

Thirdly, the concept implies a predisposition to avoid open conflict. Comity is traditionally associated with 'deference', where one system defers to another. However, the concept opens up for analysis the wider range of choices involved in managing relationships in order to avoid conflict. Comity maps a path away from the kind of frozen positions associated with the old Cold War. At the same time, it steps back from claims that a new consensus is emerging around the nature of a new global order.

\section{THE POTENTIAL OF COMITY}

The possibilities of comity depend on 'like-mindedness'. 'Like-mindedness' defines the groups that can engage productively in rulemaking in the 'in-between' space between the fully multilateral and the unilateral.

Like-mindedness stands for a common way of thinking about the content of new rules and to congruent ways of making rules. It allows governments that share expectations about underlying values, rulemaking procedures and behaviour to move ahead with common rulemaking and to sidestep those who do not share the same values. It shapes the form of the organisations they set up for rulemaking. In addition, the like-minded can adopt mutually supportive policies to extend the reach of their common approaches to the outside world. Where other countries buy into the provisions, the rules can be adopted in ever-wider circles beyond the group itself. Rulemaking by like-minded groups can stand on its own. It can also provide a pathway to the later adoption of rules on a fully international basis.

Like-mindedness is a principle both of inclusion and of exclusion. It can be applied at the level of governments and it can also be applied at the level of people and their groups. It is applied at both levels in this book. At the level of governments, it is used to distinguish between democratic and autocratic governments. At the level of people, it is used to refer to the professionals and experts who are key to their rulemaking.

Like-mindedness has both strengths and flaws. At the level of like-minded governments, the great strength is that the processes for rulemaking are simplified and eased. The weakness is that the process of widening the adoption of rules is not an automatic one. The response of the wider world is often uncertain and tension inevitable. At the level of people, 'in groups' can define their own boundaries for good reasons, such as to maintain professional standards and in order to narrow their focus on to practical problems. 'In groups' can also fall prey to 'group think' and exclude other actors, or narrow down their agenda, in ways that are damaging to public policy and to wider social norms. 
They can become overpowerful. The analysis therefore addresses both sides of the coin.

\section{THE RELATIONSHIP WITH DEMOCRACY}

In international rulemaking we now face a fundamental impasse based on the different underlying characters of governments. On the one side stand democratic countries that wish to assure the mutual coherence and congruence of the values applicable to new areas of rulemaking with their own central values. On the other side are authoritarian countries whose values are quite different and whose rulers are only interested in the protection and exercise of their own power. They are unconstrained by domestic opinion. We cannot wish away this divide.

Even democratic governments that share fundamental underlying values may still not see eye to eye on where to draw the actual lines in the new areas of international concern. There are different varieties of democracy, and democratic opinion can reasonably differ on where exactly to draw the line in such areas of public policy as cyber security, the protection of personal data or the role of artificial intelligence (AI), or on the safeguards around genetic engineering and modification.

However, despite such differences, countries that share democratic values in their domestic political organisation will recognise the centrality of their core values for the new areas of international rulemaking. They will share common concerns when the same values that underpin their domestic political systems become salient in the context of international rulemaking. Aware of the fragility of their own systems, they will wish to defend and project their own core values in international rulemaking. Their own rulemaking can provide the model for the wider world.

\section{THE WARNINGS AGAINST COMITY}

There are many warnings about what happens when separate and distinctive systems of law and rulemaking try to operate side-by-side in the same space. These warnings mainly derive from the academic literature around 'legal pluralism'.

There are two main warnings. The first is that history suggests that pluralism does not lead towards a wider consensus. Instead, it leads to inevitable rivalry and conflict between jurisdictions. If so, then the focus of comity on ways to avoid conflict and to provide a pathway to a wider international adoption of rules will end in disappointment. The second is that the most powerful actors will dominate the rivalry. If so, then the focus of comity on managing norma- 
tive differences rather than on power relationships will end in deception. Both warnings remain valid.

The potential for conflict between like-minded democratic groups and other jurisdictions cannot be avoided. Like-minded groups may prefer to avoid challenge, prefer to remain silent in the face of disagreement with others outside the group, provide incentives and hope to persuade them to converge in their own rulemaking. However, persuasion and incentives will not always work. In the presence of unresolved disagreements, the influence of other jurisdictions reaches in; the like-minded groups will want the influence of their rulemaking to reach out. Friction is inevitable.

The danger that the 'powerful' will dominate takes two forms. The first, very traditional, form is that rulemaking will be dominated, at the level of governments, by the most powerful states. In cases where the 'powerful' stay outside like-minded groups, the classic response lies in the formation of new alliances of the like-minded and the strengthening of old relationships. In cases where the 'powerful' are participants within the group, later analysis points to the ways that smaller participants within like-minded groups can defend themselves from dominance by their most powerful members. However, a different, second kind of power resides within like-minded groups. It is wielded at the level of people by the webs of professionals who instigate the rules in new areas. The danger is that professional elites may capture the key rulemaking processes.

Both the risk of capture within the system and the risk of conflict between systems raise questions about the legitimacy of comity in an international setting. If like-minded democratic groups are to provide a path towards fully international rules, the legitimacy of what they do has itself to be firmly rooted.

\section{LEGITIMACY}

The observance of democratic values by like-minded groups within their own domestic settings does not confer automatic legitimacy on what they do together in an international setting. It appears directly contrary to the two main ways of visualising an ideal harmonised world. It runs against the ideal of a global authority based on global values. It also runs against the alternative vision of rules interpreted and legitimised by validation from all the different countries in the world.

There is, however, a third way of understanding legitimacy, based on the voluntary acceptance by individuals of the mode of rulemaking. It is the closer rooting in the individual acceptance of rulemaking that underpins the claim of like-minded democratic groups to have legitimacy for what they do. Coherence between the content of their rules and what democratic countries stand for, and the congruence of their rulemaking procedures with democratic 
processes, together enable like-minded democratic groups to claim a closer relationship with the individual acceptance of rulemaking than other forms of international rulemaking.

$* * * * *$

The wave of hope that accompanied the effort to build an international rule of law in the immediate post-war world did not survive the confrontation of the Cold War. A second wave of optimism that accompanied the fall of communism in the Soviet Union is also foundering. The hope that we could see a natural dynamic at work, taking us from law centred on the state to a comprehensive system of international law under some kind of global institutional framework, is receding. Rivalries between the changing powers in the world have acquired a new edge. Fundamental norms have not converged.

In a world where there exist basic divergences in values between democratic and authoritarian countries, we cannot rely on bodies with global memberships to be able to agree on international rules of behaviour where we now need them. At the same time, we cannot rely on the great powers in the world to set aside their rivalries. We thus need to look again in depth at the potential for rulemaking among those like-minded groups that share basic democratic values and that bring these values to the negotiating table. We can hope that their efforts can lead in turn towards a wider international consensus.

\section{THE ORGANISATION OF THE ANALYSIS}

The analysis starts with a brief description of the reversal of globalisation. It attributes the re-emergence of borders to fundamental differences in regulatory approaches to the 'knowledge economy'. The differences reflect the political character of domestic regimes. In turn, disagreements about the values applicable in the knowledge economy at the domestic level block agreement on rulemaking in fully international bodies at the international level. The differences provide the incentive for like-minded countries to get together among themselves in order to make the rules (Chapter 2).

The analysis then turns to defining the different settings and features of side-by-side rulemaking and the wider context for like-minded democratic groups in international rulemaking. It compares the features of like-minded groups to transnational accounts of international relationships (Chapter 3).

The analysis moves on to examine the kinds of bodies, actors and techniques of rulemaking associated with like-minded democratic groups. The over-arching feature is that like-minded groups are 'lightly institutionalised'. Light institutionalisation is often misunderstood as 'soft'. However, 
like-minded groups draw their strength from shared normative commitments and from decentralised, congruent professionalism (Chapter 4).

Like-minded democratic groups get together to make common rules in part to defend themselves against unwanted influences coming in. They also aim to have influence beyond their membership and reach out to the world outside. The form in which like-minded groups aim to defend themselves and to have extraterritorial influence and effect beyond their borders is taken up next (Chapter 5). The menu includes both positive incentives to those outside the group to fall into line as well as the imposition of costs and penalties. The choices from the menu tilt towards penalties in cases where differences with other regimes are deeply embedded and where targeting the private sector offers the more promising path to change.

The analysis then turns to the warnings about rulemaking by like-minded groups. It examines, firstly, the risks of conflict with other rule makers outside the group. The management of the risk of conflict centres on 'norms about norms' - the application of those norms that are intended to manage normative disagreements. One jurisdiction in disagreement with another can choose to claim superiority, or to remain silent, or to look for compatibility (Chapter 6). The analysis looks secondly at the dangers associated with the dominance of the powerful. It focuses on the risk within the group of capture by professional practitioners (Chapter 7).

Finally, the analysis takes up the sources of legitimacy for rulemaking by the like-minded. There is no generally agreed account of legitimacy for international rulemaking. Different accounts can be offered at the global level and at the level of states, and based on the individual acceptance of rulemaking. The legitimacy of rulemaking by like-minded groups hinges on the relationship with individual acceptance (Chapter 8).

The conclusion looks at the challenges facing international rulemaking by groupings of like-minded democracies today. They need to refresh their own democratic credentials. They also need to refresh their alliances (Chapter 9). 